\title{
Patient and caregiver experience in the transition from hospital to home - brainstorming results from group concept mapping: a patient-oriented study
}

\author{
Tara Kiran MD MSc, David Wells MSc, Karen Okrainec MD MSc, Carol Kennedy MSc, \\ Kimberly Devotta MA, Gracia Mabaya MSc, Lacey Phillips MAHSR, Amy Lang PhD, Pat O'Campo PhD
}

\section{Abstract}

Background: Improving the quality of care for patients who return home after a hospital stay is an international priority; however, few jurisdictions have engaged broadly with patients and caregivers to understand what most affects their experience transitioning home. We performed Ontario-wide group concept mapping, beginning with a brainstorming phase, to understand patient and caregiver priorities in the transition.

Methods: We used group concept mapping to engage patients and caregivers who had lived experience transitioning from hospital to home in Ontario in the previous 3 years. We report on the first phase, brainstorming, conducted over 10 weeks beginning Jan. 11 , 2018 via an online survey or facilitated group discussion. Participants responded to a single focal prompt: "When leaving the hospital for home, some thing(s) that affected the experience were: ___." The study team identified recurrent concepts and overarching themes. Patients and caregivers informed the study design, recruitment and data interpretation.

Results: In all, 665 people (263 patients [39.5\%], 352 caregivers [52.9\%] and 50 people who were both patient and caregiver [7.5\%]) participated in brainstorming online, and 71 people participated in 1 of 8 group discussions. Participants identified 6 key areas affecting their experience of transition from hospital to home: home and community care, the discharge process, medical follow-up after discharge, medications, patient and caregiver education, and the kindness and caring of the health care team in hospital. Most notable were challenges with the timeliness, sufficiency, reliability and consistency of publicly funded home care services.

Interpretation: Patients and caregivers from across Ontario noted a range of issues affecting their experience transitioning from hospital to home, particularly the quality and sufficiency of publicly funded home care. Our findings will be used to inform a provincial quality standard on the transition from hospital to home.

Plain language summary: Transitioning back home after a hospital admission can be a tricky time for patients and their caregivers. Patients have experienced changes in their health and ability to function independently, and, at the same time, are relying on different parts of the health care system to work well together. We wanted to understand what most affected patient and caregiver experience in the transition from hospital to home and use our findings to develop a provincial quality standard that outlines what good care looks like when patients are discharged from hospital to home. We conducted public outreach over 10 weeks beginning Jan. 11 , 2018 to recruit patients and caregivers who had a lived experience transitioning from hospital to home in Ontario in the previous 3 years. We asked participants to brainstorm responses to a single question: "When leaving the hospital for home, some thing(s) that affected the experience were:__. . A total of 665 patients and caregivers responded to the question online, and another 71 via a facilitated group discussion. We analyzed the data for themes and found that patients and caregivers identified 6 key areas affecting their experience transitioning from hospital to home: home and community care, the discharge process, medical follow-up after discharge, medications, patient and caregiver education, and the kindness and caring of the health care team in hospital. The most common challenges were with the timeliness, sufficiency, reliability and consistency of publicly funded home care services. Understanding what matters to patients and caregivers helps us define what good care looks like and how we should focus efforts to improve our health care system.

Competing interests: At the time of writing, David Wells, Carol Kennedy, Gracia Mabaya, Lacey Phillips and Amy Lang were employees of and Tara Kiran was an embedded clinician researcher at Health Quality Ontario. No other competing interests were declared.

This article has been peer reviewed.

Correspondence to: Tara Kiran, tara.kiran@ utoronto.ca

CMAJ Open 2020. DOI:10.9778/cmajo.20190009 
I mproving the transition from hospital to home is an important health care system priority. Much of the research about the transition from hospital focuses on reducing readmissions, partly as a strategy to reduce costs. ${ }^{1}$ But interventions to reduce readmissions have had mixed success, ${ }^{2,3}$ and there is debate about whether readmissions can be prevented through better care ${ }^{4,5}$ or whether readmission is an outcome important to patients. ${ }^{6}$ Focusing efforts on understanding and improving the patient experience may be a more fruitful approach to improving the quality of transition from hospital to home.

Engaging patients in health care design can improve service delivery and quality of care. ${ }^{7,8}$ Many organizations are trying to enhance patient engagement in direct care ${ }^{9,10}$ or have engaged patients to inform organizational-level interventions.

Our provincial quality agency was interested in engaging patients to inform a quality standard on the transition from hospital to home. We performed province-wide group concept mapping to understand patient and caregiver priorities in the transition. We began with province-wide brainstorming that sought to understand what affected the patient and caregiver experience in the transition from hospital to home.

\section{Methods}

\section{Setting and context}

The research was conducted in partnership between Ontario's agency for health care quality at the time, Health Quality Ontario (now Ontario Health [Quality Business Unit]), and a team of researchers. Ontario is Canada's most populous province, with about 14.1 million people in 2017. ${ }^{11}$ Physician and hospital services are fully insured under the provincial health insurance plan, which covers all permanent residents, but there are recognized gaps in coverage, including gaps in dental care, home and community care, and medications. ${ }^{12}$ Home and community care services are organized and delivered at the level of the health region (Local Health Integration Network).

\section{Study design and participants}

We used group concept mapping methods to engage people with lived experience as a patient or caregiver of a patient transitioning home from hospital. Group concept mapping is a participatory research method ideally suited to gather input from a large number of stakeholders to inform planning and evaluation. ${ }^{13-17}$ It involves participants in generating ideas, prioritizing emerging concepts and interpreting results (Appendix 1, available at www.cmajopen.ca/content/8/1/E121/suppl/ DC1). Group concept mapping has been used to understand patient experience ${ }^{18}$ and what good care looks like, ${ }^{19,20}$ with the results informing the development of performance measures. It has also been used to engage patients in clinical quality improvement. ${ }^{21}$

We report on the first phase of concept mapping brainstorming — which engages participants in generating ideas relevant to the research question. Research has shown that brainstorming in group concept mapping is highly effective and efficient at identifying outcomes important to patients compared to traditional qualitative methods. ${ }^{22}$

We engaged people who had lived experience as a patient or caregiver of a patient discharged home after being admitted overnight to an Ontario hospital in the previous 3 years. We defined "home" broadly to include community residences, such as an apartment or house, but also shelters, supportive housing, long-term care, rehabilitation and chronic care facilities. Caregivers could include family members or unpaid friends. Participants self-assessed whether they met the inclusion criteria. On the advice of patients and caregiver advisors, there were no age restrictions for participation.

\section{Recruitment}

In keeping with the mandate of Health Quality Ontario, recruitment was intentionally broad and inclusive. However, we also used strategies to reach participants from diverse backgrounds. We recruited participants over 10 weeks beginning Jan. 11, 2018 using the agency's social media channels and network of partner organizations. We provided pertinent patient, community and health care organizations (e.g., Meals on Wheels, Multiple Sclerosis Society of Canada, Lived Experience \& Recovery Network, Ontario Hospital Association, Association of Family Health Teams of Ontario) with materials to promote the survey (Appendix 2, available at www.cmajopen.ca/content/8/1/E121/suppl/DC1) and invited them to host a group discussion.

With the help of a community advisory group (Appendix 3, available at www.cmajopen.ca/content/8/1/E121/suppl/DC1), we undertook targeted outreach to patient groups that we hypothesized a priori as having unique perspectives but suspected were difficult to reach. Target populations included children, long-term care residents, rural residents, those with mental health issues, newcomers, people who did not speak English, people who were homeless or experiencing housing instability, and members of the LGBTQ2S community. Members of community advisory groups supported their community groups to engage in group discussions or online (e.g., by providing language interpretation as needed).

We monitored participant demographic characteristics and intensified recruitment strategies for target populations accordingly. There was no monetary incentive to participate. Health Quality Ontario committed to sharing the results with participants.

\section{Data collection}

Participants could engage in brainstorming in 1 of 2 ways: via on online survey hosted on Health Quality Ontario's webpage or via a facilitated group discussion. In both cases, participants were asked to provide responses to a single focal prompt: "When leaving the hospital for home, some thing(s) that affected the experience were: __." Instructions clarified that participants could report both positive and negative experiences, and could provide multiple responses. We tested and refined the focal prompt based on feedback and pilot testing from Health Quality Ontario's Patient, Family and Public Advisors Council, and Patient Advisors Network. 
Participants were asked to complete demographic questions after answering the focal prompt online. Online responses were anonymous and were exported into Microsoft Excel for analysis.

Facilitated group discussions were hosted by interested patient, community and health care organizations. We included this participation option to maximize the diversity of respondents and to support participation for people with lower language and electronic literacy. Members of the study team and of Health Quality Ontario produced a facilitation guide (Appendix 4, available at www.cmajopen.ca/content/8/ 1/E121/suppl/DC1), facilitation slides (Appendix 5, available at www.cmajopen.ca/content/8/1/E121/suppl/DC1) and live webinars to support organizations to host a group session.

All sessions were cofacilitated or guided by a member of the agency's Patient and Public Partnering team. Sessions lasted 30-60 minutes and were not audio-recorded. The host organization was responsible for documenting responses to the focal prompt and collecting demographic information of participants, and forwarding these to Health Quality Ontario. The agency received group responses without any participant identifiers and entered these manually into Excel.

\section{Data analysis}

We analyzed all responses to the focal prompt from the online survey and group discussion together using thematic analysis. ${ }^{23,24} \mathrm{We}$ included responses even if demographic information was incomplete. Eight members of the research team (T.K., D.W., K.O., C.K., K.D., G.M., L.P., P.O.) read and coded the data as follows. First, they individually selected 200 items at random and thematically coded them, keeping and coding items that were responsive to the focal prompt, and eliminating items that were off topic or duplicates. The team members then met and discussed their codes and agreed on a single set of 6 codes that applied to the 200 items. Subsequently, the remaining items were assigned to team members to eliminate items that were not relevant, to apply the initial set of thematic codes and to flag any items that were responsive to the focal question but did not fall into the initial thematic codes. There was overlap in assignment of items to team members to support consistent coding. Discrepancies and uncertainty were resolved via email and face-to-face meetings.

The team reviewed responses from participants whose transition was to a long-term care home, rehabilitation centre or chronic care hospital separately to determine whether additional codes were needed; ultimately, the 6 existing thematic codes were applied to all the items, with no new thematic codes emerging.

Once all items were eliminated or coded, 2 team members each worked with items within a single thematic code. The team members then identified 5-15 statements (concepts) to represent that code. Given that some categories had dozens of items, this required a second round of thematic coding within these large initial groupings. This helped to ensure that key themes within the initial categories were represented in the final statements.
After the second round of thematic coding, the team reviewed the coded items and together developed the final statements. The team tried to have each statement reflect the language used by participants in their responses. The team aimed to identify up to 50 unique statements, a manageable number for use in the sorting and rating phase of concept mapping. ${ }^{13,25}$ As a final check, the principal investigator (T.K.) re-reviewed all coded items and modified or confirmed the final statements.

We summarized participants' demographic characteristics using simple proportions.

All analyses were conducted in Excel, which offered sufficient functionality for thematic coding given the relatively short responses to the focal prompt.

\section{Patient engagement}

Members of Health Quality Ontario's Patient, Family and Public Advisors Council identified that improving transition from hospital to home was a priority and were involved in the initial study design. They informed the engagement approach, participant inclusion criteria and brainstorming question.

We formed a community advisory group composed of patients, caregivers, and representatives from selected community and health care organizations to help with targeted engagement (Appendix 3). The community advisory group also informed study design and helped with interpretation of results.

Health Quality Ontario's Patient Advisors Network over 500 patients, families and members of the public from across the province - helped to recruit survey participants.

Finally, we reviewed the study design, proposed outreach and preliminary results with the Transitions Between Hospital and Home Quality Standard Advisory Committee. The committee includes people with lived experience as well as clinicians, administrators and policy experts who advise Ontario Health (Quality Business Unit) on the development of the quality standard.

A brief summary of preliminary results from the brainstorming were shared with all participating organizations and posted on the agency website. No individual patient partners met the criteria for study authorship.

\section{Ethics approval}

The protocol was reviewed and discussed with the St. Michael's Hospital Research Ethics Board and deemed not to constitute research under Article 2.5 of the Tri-Council Policy Statement: Ethical Conduct for Research Involving Humans and to not require informed consent from participants.

\section{Results}

In all, 665 people (263 patients [39.5\%], 352 caregivers [52.9\%] and 50 people who were both patient and caregiver [7.5\%]) responded to the focal prompt online, and 71 people participated in 1 of 8 group discussions. An additional 287 people began the online survey but did not respond to the focal prompt. 
Group discussions were facilitated in 5 health regions and were organized by Local Health Integration Networks, primary care centres, hospitals and patient advocacy organizations (Table 1). We did not consistently receive demographic information about participants in the facilitated group discussion; self-reported demographic characteristics of participants who responded to the online survey are presented in Table 2. The majority (635 [95.5\%]) of online participants reported that the patient was discharged to an apartment, house or other community residence; $30(4.5 \%)$ went to a long-term care home; and $54(8.1 \%)$ went to a rehabilitation facility, chronic care hospital or other destination (numbers total $<665$ as some participants specified more than 1 destination if they were responding as both a patient and a caregiver). Participants came from different communities spanning Ontario's geography (Figure 1).

Participants collectively submitted 2704 responses to the focal prompt. Most responses (about 85\%) described negative experiences. We identified 6 overarching themes - home and community care and supports, medical follow-up after discharge, discharge process, patient education, medications, and kind and caring health care team in hospital — and 52 related statements (concepts). Themes and example quotes were shared with people with lived experience who were on our advisory groups or participated in this or later engagements; themes resonated as reflective of their experience.

\section{Home and community care and supports}

The largest number of participant responses were related to home and community care, and most described negative experiences (Table 3). Many participants commented about the poor quality of home care, including the timeliness and sufficiency of services, and the consistency and reliability of home care staff. Many reported that home care was not in place for days or weeks once the patient was home, sometimes contrary to what they had been told in hospital. Home care staff changed frequently and often cancelled with short notice or no notice. Many participants described not having enough care, particularly for bathing and dressing, and some specifically noted that patients and caregivers needed to advocate to get the care they needed. Some mentioned challenges with coordination and staffing when patients moved between 2 Local Health Integration Networks.

Participants reported challenges accessing a range of community supports, including outpatient mental health support. Experiences with home palliative care were mixed. Participants expressed that there was often a long wait for publicly funded physiotherapy and rehabilitation supports, and that the publicly funded care eventually provided was insufficient to meet their need. Participants also noted that housecleaning, laundry and other support services were not covered by the home care agency and that arranging these was challenging.

Many patients described the important role their family and friends played in supporting their recovery at home, whereas others described difficulties in living alone after discharge with no family support. Some participants commented on the minimal respite services for caregivers.

\section{Medical follow-up after discharge}

Participants reported both positive and negative experiences accessing their family doctor or specialist in a timely way after discharge (Table 4). Some appreciated having a trusted family

\begin{tabular}{|c|c|c|c|}
\hline Organization & Geographic location & Facilitation & $\begin{array}{l}\text { No. of } \\
\text { attendees }\end{array}$ \\
\hline $\begin{array}{l}\text { Country Roads Community } \\
\text { Health Centre }\end{array}$ & Portland & $\begin{array}{l}\text { Facilitated by member of the study's } \\
\text { community advisory group }\end{array}$ & 8 \\
\hline $\begin{array}{l}\text { Waterloo Wellington LHIN } \\
\text { Patient and Family Advisory } \\
\text { Committee }\end{array}$ & Waterloo & $\begin{array}{l}\text { Facilitated by Health Quality Ontario } \\
\text { staff }\end{array}$ & 20 \\
\hline $\begin{array}{l}\text { North East LHIN Patient } \\
\text { and Family Advisory } \\
\text { Committee }\end{array}$ & North Bay & $\begin{array}{l}\text { Facilitated by Health Quality Ontario } \\
\text { staff through Ontario Telemedicine } \\
\text { Network }\end{array}$ & 16 \\
\hline Ottawa Cancer Foundation & Ottawa & Facilitated by local member & 5 \\
\hline One More Thing & Online (Facebook group) & $\begin{array}{l}\text { Facilitated by Health Quality Ontario } \\
\text { staff }\end{array}$ & 6 \\
\hline Powerhouse Project & St. Catharine's & Facilitated by local member & 5 \\
\hline $\begin{array}{l}\text { St. Michael's Hospital } \\
\text { Patient and Family Advisory } \\
\text { Committee }\end{array}$ & Toronto & $\begin{array}{l}\text { Cofacilitated by hospital staff member } \\
\text { and study team member (T.K.) }\end{array}$ & 5 \\
\hline Champlain LHIN & Ottawa & $\begin{array}{l}\text { Facilitated by member of Health } \\
\text { Quality Ontario's Patient, Family and } \\
\text { Public Advisors Council }\end{array}$ & 6 \\
\hline
\end{tabular}


Table 2: Self-reported demographic characteristics of online participants

\begin{tabular}{|c|c|}
\hline Characteristic & $\begin{array}{c}\text { No. }(\%) \text { of } \\
\text { participants } \\
n=665\end{array}$ \\
\hline \multicolumn{2}{|l|}{ Role* } \\
\hline Patient & $263(39.5)$ \\
\hline Caregiver & $352(52.9)$ \\
\hline Both & $50(7.5)$ \\
\hline \multicolumn{2}{|l|}{ Patient age $(n=608)$} \\
\hline$\leq 5$ & $9(1.5)$ \\
\hline $6-18$ & $23(3.8)$ \\
\hline $19-25$ & $15(2.5)$ \\
\hline $26-49$ & $100(16.4)$ \\
\hline $50-64$ & $139(22.9)$ \\
\hline $65-79$ & $185(30.4)$ \\
\hline$\geq 80$ & $137(22.5)$ \\
\hline \multicolumn{2}{|l|}{ Patient gender $(n=607)$} \\
\hline Female & $357(58.8)$ \\
\hline Male & $244(40.2)$ \\
\hline Other† & $6(1.0)$ \\
\hline \multicolumn{2}{|l|}{ Discharge destination $\ddagger$} \\
\hline $\begin{array}{l}\text { Apartment, house, other place of } \\
\text { residence }\end{array}$ & $635(85.8)$ \\
\hline Nursing or long-term care home & $30(5.8)$ \\
\hline $\begin{array}{l}\text { Short-term rehabilitation facility, chronic } \\
\text { care hospital or "other" }\end{array}$ & $54(8.0)$ \\
\hline \multicolumn{2}{|l|}{ Other patient characteristics $(n=591)$} \\
\hline $\begin{array}{l}\text { Lives in community that is parallel to or } \\
\text { north of Sudbury }\end{array}$ & $61(10.3)$ \\
\hline $\begin{array}{l}\text { Lives in community with } \\
\leq 30000 \text { residents }\end{array}$ & $149(25.2)$ \\
\hline $\begin{array}{l}\text { Would take more than } 60 \text { min by car to get } \\
\text { to hospital where they were last admitted }\end{array}$ & $83(14.0)$ \\
\hline $\begin{array}{l}\text { Admitted to hospital more than once in } \\
\text { previous year }\end{array}$ & $202(34.2)$ \\
\hline $\begin{array}{l}\text { Does not have family doctor or nurse } \\
\text { practitioner to attend to regular medical } \\
\text { needs }\end{array}$ & $31(5.2)$ \\
\hline $\begin{array}{l}\text { Does not have family or friends who can } \\
\text { help when needed }\end{array}$ & $33(5.6)$ \\
\hline Lives alone & $148(25.0)$ \\
\hline $\begin{array}{l}\text { Sometimes has difficulty making ends } \\
\text { meet at end of month }\end{array}$ & $79(13.4)$ \\
\hline $\begin{array}{l}\text { Does not have college diploma or } \\
\text { university degree }\end{array}$ & $172(29.1)$ \\
\hline $\begin{array}{l}\text { Came to Canada as immigrant within } \\
\text { previous } 10 \mathrm{yr}\end{array}$ & $11(1.9)$ \\
\hline $\begin{array}{l}\text { Is most comfortable speaking language } \\
\text { other than English with health care } \\
\text { provider }\end{array}$ & $46(7.8)$ \\
\hline $\begin{array}{l}\text { Identifies as member of LGBTQ2S } \\
\text { community }\end{array}$ & $16(2.7)$ \\
\hline $\begin{array}{l}\text { Has physical, sensory or developmental } \\
\text { disability }\end{array}$ & $126(21.3)$ \\
\hline $\begin{array}{l}\text { Admitted to hospital because of mental } \\
\text { health condition }\end{array}$ & $23(3.9)$ \\
\hline Has dementia & $55(9.3)$ \\
\hline \multicolumn{2}{|c|}{$\begin{array}{l}\text { *Participants could respond as a patient or caregiver or both. Caregiver } \\
\text { participants reported the characteristics of the person they were caring for. } \\
\text { †Some respondents reported "other" because they were responding based on } \\
\text { the experiences of more than } 1 \text { person (e.g., } 2 \text { different patients). } \\
\text { fCaregivers who were also patients responded with more than } 1 \text { location to indicate } \\
\text { the discharge location for themselves and the patient, if they were different. }\end{array}$} \\
\hline
\end{tabular}

doctor, whereas others noted they had no family doctor and were not given help to find one. Some participants left hospital with specialist appointments clearly arranged, but others expressed frustration at having to arrange these themselves, in some cases without clear direction. Participants noted whether their family physician or health care staff at their long-term care home or rehabilitation centre had information about the admission. Participants also recounted difficulties getting to follow-up appointments because of challenges with mobility, distance, and related transportation or cost, with some wishing their doctor made house calls.

\section{Discharge process}

Several participants described negative experiences related to the timing of discharge (Table 5). Many felt that they or their loved one were discharged too early, before recovery, with some thinking this contributed to a subsequent hospital visit. Some described the discharge process as rushed, in some cases because someone else was waiting for the bed. In contrast, other participants said there were unnecessary delays in the expected discharge due to paperwork.

Experiences relating to communication and shareddecision making were mixed. Some participants described being involved as a patient or caregiver in the discharge process, whereas others, particularly caregivers, discussed being left out of planning although they would be caring for the patient at home.

Participants described not being given enough notice about the discharge time; in some cases, this resulted in logistical difficulties for caregivers. Participants specifically commented on not being able to see the doctor at the time of discharge. Some also expressed challenges with transportation home.

\section{Patient education}

There were mixed experiences with receiving a written discharge summary that included instructions (Table 6). Many participants mentioned they were uncertain who to call if there was a problem after discharge, although some were given the number of a doctor or staff member. Some participants noted receiving clear information about self-care and recovery once home, whereas others described not having information on how to care for themselves or use new equipment.

\section{Medications}

Some participants had medication effects, adverse effects and schedules explained clearly to them before discharge, whereas others did not (Table 7). Several described challenges managing complex new medication regimens at home and not having sufficient instruction or support to do so. Some participants mentioned the high out-of-pocket costs for medication. A few noted difficulty filling their prescription in a timely way after discharge.

\section{Kind and caring health care team in hospital}

Many participants recounted how doctors, nurses and other hospital staff were kind and caring (Table 8). Some described 


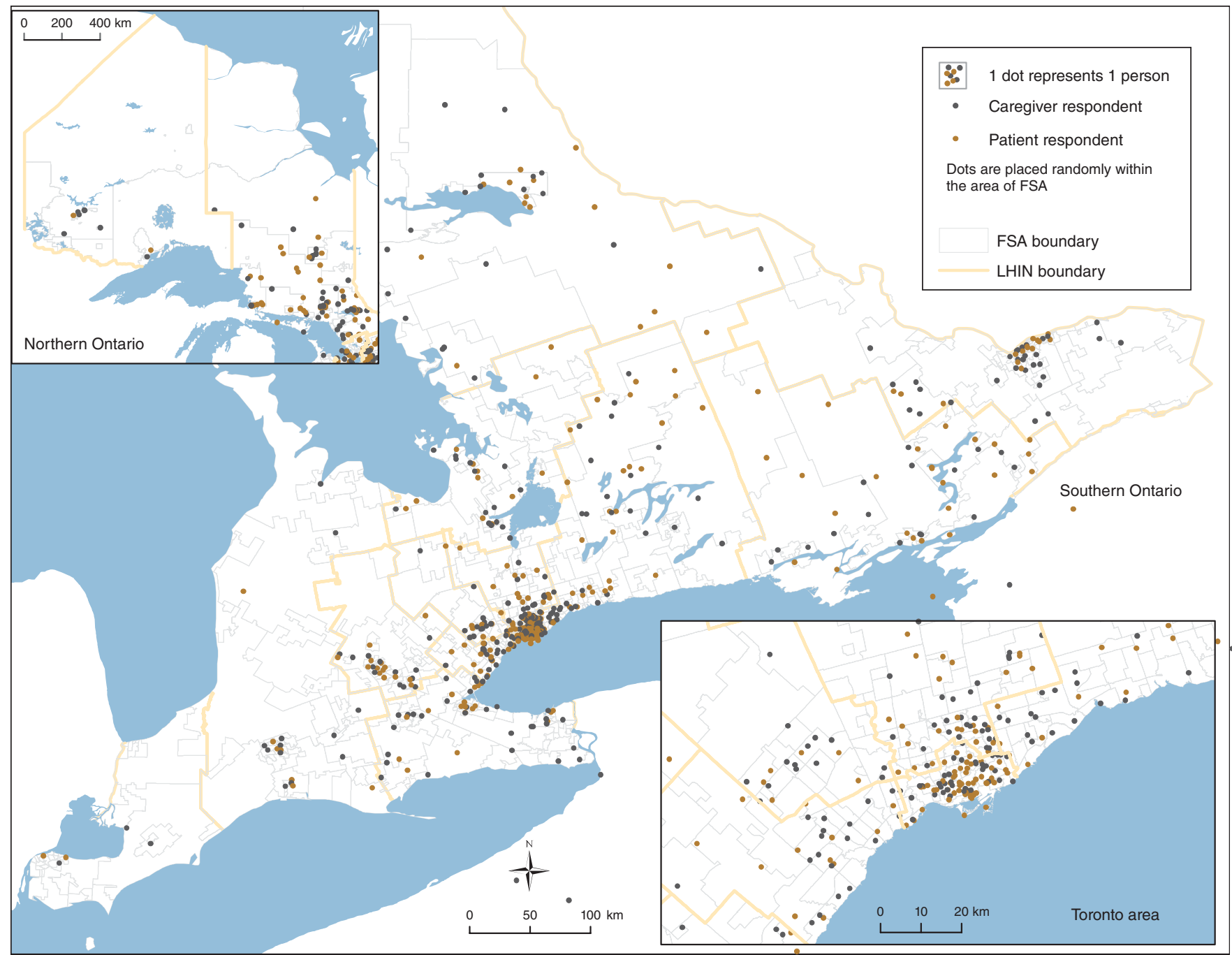

Figure 1: Geographic distribution of patients and caregivers who responded to the focal prompt online and provided the first 3 digits of their postal code. Caregivers reported postal codes of the person(s) they were caring for. Note: FSA $=$ forward sortation area, LHIN $=$ Local Health Integration Network.

staff as being rude or inattentive. Many noted whether their doctor or nurse took time to listen and answer their questions. A few participants described not having accommodations for people with specific physical needs (e.g., visual or hearing impairment) or not having language or cultural needs met. Many felt that how they were treated in hospital directly affected their recovery at home.

\section{Interpretation}

In this patient-oriented study, in which we consulted with a large, diverse group of patients and caregivers across a vast geographic area who had lived experience of transitioning from hospital to home, patients and caregivers highlighted several areas that affected their experience in the transition from hospital to home. The most commonly reported challenges related to home and community care, with many participants reporting that publicly funded home care services were not timely, sufficient, reliable or consistent. Many relied on family, friends, private services or charities to fill the gap. The second most notable theme related to the discharge process, including timing, communication, and involvement of patients and caregivers in the planning process. The largest proportion of positive experiences related to kindness and caring of individual physicians, nurses and hospital staff.

The gaps we found in the availability and quality of home care echo concerns raised in the 2015 final report from Ontario's Expert Group on Home and Community care. ${ }^{26}$ In 2017, home care delivery in Ontario underwent substantial reforms, with responsibility transferring from regional agencies to the Local Health Integration Network itself. ${ }^{27}$ A year after these reforms, patients and caregivers in our study continued to report numerous challenges with home care services. Implementing recommendations from a recent expert panel to ensure a consistent and transparent level of service may address some of these concerns..$^{28}$ 
Table 3 (part 1 of 2): Patient and caregiver views on factors affecting the experience of transitioning from hospital to home: home and community care supports

Unique concept

Representative quote*

Home care support being in place when arriving home from hospital

Consistency of home care staff

Reliability of home care staff

Sufficiency of publicly funded home care

Having to advocate to get enough home care level of home care between communities

Consideration of home safety and accessibility during discharge planning

Medically necessary equipment being in place at home when discharged

Cost of medically necessary equipment

Availability of community mental health supports

Availability of community palliative care supports

Timeliness of publicly funded community-based physiotherapy, occupational therapy and other rehabilitation supports
After moving home, it took over 3 weeks before we were linked to any home support services. (Female patient, age 26-49)

My father received home care after a week, not 24 hours, as indicated by hospital discharge staff. (Caregiver of male patient, age 50-64)

No consistency of care ... too many different PSWs; at one point, my mother (with dementia) had 8 different PSWs in 1 week. (Caregiver of female patient, age $\geq 80$ )

My mother didn't have enough home care support that was consistent; she had dementia, and she had 14 different workers in 7 days. (Caregiver of female patient, age $\geq 80$ )

Several days after [my husband came] home, case workers started to arrive to assess my husband to determine what I will be needing for home care help. Finally got some help coming to [the] house but not enough hours ... as well as numerous no-shows as well as no phone calls to say they are not coming. Just because my husband cannot talk does not mean that his caregiver cannot talk to him. (Caregiver of male patient, age 65-79)

Three times a PSW never showed up to help, and no call was sent to let us know they could not make it. (Caregiver of male patient, age 50-64)

We had to offset home care with private and family support. (Caregiver of male patient, age $\geq 80$ ) Limited hours offered by CCAC to support a failing 90-year-old woman in her own apartment. (Caregiver of female patient, age $\geq 80$ )

After leaving the hospital, my loved one did not have enough care for both morning (wake/bathe/dress) and evening (dinner preparation, clean-up, undress/hygiene/bedclothes) routine. (Caregiver of female patient, age $\geq 80$ )

Had little to no help from CCAC coordinators. Had to fight to get help. (Female patient, age 50-64) Patients who cannot express themselves well [because of] cognitive or other barriers are roughly treated, and, if there is no advocate, it doesn't get addressed. (Caregiver of female patient, age 65-79)

It took a lot of work to access the home care services my loved one required and multiple phone calls. (Caregiver of female patient, age $\geq 80$ )

Home care is based on geography. When my relative moved from home to respite care back to her apartment, her care coordinator kept changing. (Caregiver of female patient, age $\geq 80$ )

There was a gap with CCAC because there were 2 LHINs involved, but once the communication was done, we were contacted. (Caregiver)

There was no consideration whether the home environment was safe to go back to. It wasn't, but the hospital didn't care. They said it wasn't their problem. (Caregiver of male patient, age 65-79)

When I took my brother home, his apartment was not accessible, and I had to make all the necessary changes to help. (Caregiver of male patient, age 26-49)

I was not given enough time to arrange how to get my necessary equipment. (Female patient, age 50-64)

CCAC did not have the equipment ready for us when we arrived home. It took 2 days to receive a crucial piece of equipment. (Caregiver of female patient, age $\geq 80$ )

All the needed equipment - canes, walkers, raised toilet seats and bath seats - were bought by the patient's family. (Caregiver of male patient, age 65-79)

Beds, support equipment free for 28 days. Is it expected that a person is back to normal in 28 days????

The [Assistive Devices Program] does not cover all the equipment. (Caregiver of female patient, age $\geq 80$ )

Mental health support was not considered or offered. (Caregiver of male patient, age 6-18)

A suicidal child was discharged home; connection was made with community agency, but 1-year wait time for intensive therapy. (Caregiver)

Lack of community resources for patient. (Caregiver of person age $\geq 80$ )

Palliative care doc was accessible and responsive. He came late at night, explained everything. He answered texts directly and quickly. (Caregiver of female patient, age 50-64)

Community therapy services were only available on a fee-for-service basis while waiting for 10 weeks for an OHIP-funded program. (Caregiver of male patient, age 19-25)

Six weeks after my hospital discharge, I still had to wait 3 weeks for CCAC, [occupational therapy] and [physiotherapy]. (Female patient, age 65-79) 
Table 3 (part 2 of 2): Patient and caregiver views on factors affecting the experience of transitioning from hospital to home: home and community care supports

\begin{tabular}{|c|c|}
\hline Unique concept & Representative quote* \\
\hline \multirow{2}{*}{$\begin{array}{l}\text { Sufficiency of publicly funded } \\
\text { community-based } \\
\text { physiotherapy, occupational } \\
\text { therapy and other rehabilitation } \\
\text { supports }\end{array}$} & $\begin{array}{l}\text { [Physiotherapy] only once per week is not enough for someone who could perhaps learn to be mobile } \\
\text { and more self-sufficient. Again, we are lucky to afford our own support, but this shouldn't be necessary. } \\
\text { (Caregiver of person age } \geq 80 \text { ) }\end{array}$ \\
\hline & $\begin{array}{l}\text { [The] only [rehabilitation] was five 1-hour visits paid for by OHIP in second month after surgery. (Female } \\
\text { patient, age 65-79) }\end{array}$ \\
\hline $\begin{array}{l}\text { Availability of support services } \\
\text { such as housecleaning, } \\
\text { laundry and meals }\end{array}$ & $\begin{array}{l}\text { People who need more supportive care are given restricted [care] — only bathing or extremely minor } \\
\text { assistance. Of no real help to keep people housed independently; their home is left unclean, and no } \\
\text { help with food. I needed someone to help with some cleaning. (Caregiver of female patient, age } \\
65-79)\end{array}$ \\
\hline \multirow[t]{2}{*}{$\begin{array}{l}\text { Arranging support services } \\
\text { such as housecleaning, } \\
\text { laundry, and meals }\end{array}$} & $\begin{array}{l}\text { The need to figure out where to find support services for services beyond what CCAC would provide } \\
\text { [such as] housecleaning, laundry for someone with very limited income. (Caregiver of male patient, age } \\
65-79 \text { ) }\end{array}$ \\
\hline & $\begin{array}{l}\text { Community services were not in place, and [patients are expected to organize] support such as CCAC, } \\
\text { Wheel-Trans. (Facilitated group participant) }\end{array}$ \\
\hline \multirow[t]{2}{*}{$\begin{array}{l}\text { Reliance on family and friends } \\
\text { to provide care after discharge }\end{array}$} & $\begin{array}{l}\text { No one is available to get my mom to bed at night, so we have to do it. We go from } 6: 30 \text { to } 10 \text { or } 11 \text { at } \\
\text { night and get up for work at 5:30 am. (Caregiver of female patient, age } 65-79 \text { ) }\end{array}$ \\
\hline & $\begin{array}{l}\text { After leaving hospital, my family member didn't have enough home care support to help him bathe and } \\
\text { dress, so my spouse had to take time off work to assist his father. (Caregiver of male patient, age } \geq 80 \text { ) }\end{array}$ \\
\hline \multirow{3}{*}{$\begin{array}{l}\text { Living alone without family and } \\
\text { friend support }\end{array}$} & I live alone and had no support with meal preparation. (Facilitated group participant) \\
\hline & $\begin{array}{l}\text { Great concern for people sent home without family to advocate for and help them. (Caregiver of female } \\
\text { patient, age } \geq 80 \text { ) }\end{array}$ \\
\hline & I lived alone and was scared to be by myself. (Female patient, age $26-49$ ) \\
\hline \multirow{2}{*}{$\begin{array}{l}\text { Assumptions about family and } \\
\text { friend support during } \\
\text { discharge planning }\end{array}$} & $\begin{array}{l}\text { Disheartening. It is unfair to assume family members could just drop everything to be home with their } \\
\text { loved ones, especially after long, unexpected illness. (Caregiver of female patient, age } \geq 80 \text { ) }\end{array}$ \\
\hline & $\begin{array}{l}\text { No questions about home environment - it seemed to be assumed l'd be there } 24 / 7 \text {. (I was). (Caregiver } \\
\text { of male patient, age 65-79) }\end{array}$ \\
\hline \multirow[t]{2}{*}{ Respite for caregivers } & $\begin{array}{l}\text { My dad and mom moved into my sister's house as qualified help was not available on a consistent basis } \\
\text { (not even private care). My sister received daily calls of no care available. In } 3 \text { months, she has received } \\
\text { respite twice so she could buy groceries. (Caregiver of person age } \geq 80 \text { ) }\end{array}$ \\
\hline & $\begin{array}{l}\text { Respite care has been meagre. It's a struggle to get } 1 \text { day away from the house to be able to travel out of } \\
\text { town for shopping, business. (Caregiver of female patient, age } \geq 80 \text { ) }\end{array}$ \\
\hline
\end{tabular}

Note: $\mathrm{CCAC}=$ Community Care Access Centre, LHIN = Local Health Integration Network, OHIP = Ontario Health Insurance Plan, PSW = personal support worker. ${ }^{*}$ Respondent age and gender are provided when available; caregiver respondents provided the age and gender of the patient they were caring for.

Our findings also underscore the importance of shared decision-making and clear communication during the transition from hospital to home. Patients and their caregivers wanted to be involved in discharge planning, have their questions answered, understand their medications and know how to perform self-care once home. Lack of patient and caregiver involvement in discharge planning is a known gap. ${ }^{29-31}$ Other studies have shown that patients attribute readmissions to being discharged too early and not having their concerns addressed. ${ }^{32,33}$ Informational continuity among hospital, patients and families, and outpatient settings is another known challenge ${ }^{34-36}$ that was echoed in our findings and is the subject of interventions under evaluation. ${ }^{37}$ Like us, others have noted how kindness and caring by the care team in hospital can affect the transition from hospital to home. ${ }^{38}$

Our study highlights the limits of the coverage of Ontario's public health insurance and how these conflict with patient and caregiver expectations. Policy experts have long noted that Canada has deep public coverage for a narrow basket of services, specifically hospital, diagnostic and physician services. ${ }^{39}$ Our study revealed challenges even within this narrow basket, including lack of a family doctor and pressure on hospital beds, leading to people feeling pushed out. Bigger challenges related to out-of-pocket costs for medications, equipment, transportation and home support services, such as meal preparation and housecleaning. People noted limited coverage for services such as physiotherapy and home care; some could afford to pay privately for these services, but others could not.

\section{Limitations}

Study participants came from varied geographic, medical and social backgrounds, but we had limited success recruiting newcomers and people who did not speak English or French. Our initiative was not designed specifically to understand or address the unique needs of Ontario's Indigenous communities; Indigenous health experts we spoke with recommended 
Table 4: Patient and caregiver views on factors affecting the experience of transitioning from hospital to home: medical follow-up after discharge

Unique concept

Representative quote

Timely follow-up with family doctor, nurse practitioner or specialist
My family doctor, who is a member of [primary care organization], called to arrange a follow-up appointment. (Female patient, age 50-64)

My family doctor knew my daughter was admitted to hospital because I phoned to let her know. I knew that, if we ran into trouble after discharge, our doctor would fit us in to be seen. (Caregiver of female patient, age $\leq 5$ )

Told to call [the doctor's] office (which was stated on a form they gave me) in 6 weeks. When I called, the nurse laughed and said [the doctor] hadn't seen patients that he had operated on for more than 6 months prior to my operation. I kept calling, and it took over a year to see him. (Female patient, age 65-79)

Having a trusted family physician

No attempt to connect me with a family physician was made by [hospital]. (Male patient, age 65-79) I had a trusted family doctor that I could consult if I was uncertain about anything. (Female patient, age 50-64)

Having specialist follow-up arranged or being able to arrange it

Discharge summary listed 2 critical follow-ups needed within 1 week: cardiology and nephrology clinics - NEITHER appointment was made when we left hospital. (Female patient, age 50-64)

Clear, concise written instructions for follow-up appointments with various doctors were given, so that was a handy guide. (Female patient, age 65-79)

Family physician receives complete and timely information about hospital admission

I wish that my primary care physician had received notification about my [hospital admission]. When I phoned about constipation issues and the bed sore, they had no idea what had happened or care that had been provided in the hospital and would have liked to have been more proactive on these issues. (Female patient, age 26-49)

Family doctor received nothing from hospital to allow a seamless transition home. (Caregiver of female patient, age 65-79)

Information transfer between facilities

Lack of transitional support for journey from home to hospital to retirement home which was a bridge to long-term care. Information transfer was lacking at each stage, so needs were not able to be met initially at each stage. A case manager seemed to be lacking. (Female patient, age 50-64)

Detailed notes and test results were sent to the [rehabilitation] hospital. (Caregiver of female patient, age $\geq 80$ )

Challenges getting to and from appointments once discharged

Routine visits to clinic were very difficult post stroke but were not offered through telemedicine. (Caregiver of female patient, age $\geq 80$ )

Having to follow up with a doctor whose office was out of town and I do not drive. (Female patient, age 26-49)

The hospital parking for follow-up was poor. The garage with elevators and easy access is reserved for staff. It's not just the cost of parking - it's also the ease of use. (Female patient, age 65-79)

Having a doctor who does home visits
Family doc doesn't make house calls, so totally lost contact with a doctor. How can a person in bed with discomfort in a wheelchair get an assessment from a doctor? Totally a huge logistical challenge and exhausting and painful for patient to use wheelchair taxi to go to physician office. (Caregiver of person age $\geq 80$ )

${ }^{*}$ Respondent age and gender are provided when available; caregiver respondents provided the age and gender of the patient they were caring for.

that the Ontario Health (Quality Business Unit) partner with Indigenous communities separately to focus on the impact of transitions in care on Indigenous health.

Group concept mapping methods made it feasible for us to gather open-ended responses from a large number of participants but also meant our responses were not as rich as qualitative data from semistructured interviews or focus groups. However, other research suggests that the brainstorming method identifies a higher proportion of outcomes important to patients compared to qualitative interviews. ${ }^{22}$ We did not use techniques to limit the same person from responding more than once. However, this limitation had minimal impact on our results, as the survey encouraged participants to provide as many responses to the focal question as desired.
Our recruitment was intentionally broad and inclusive; however, the fact that participants self-selected may have introduced bias into our results. Furthermore, the majority of responses about the transition experience were negative, and it is unclear to what degree this reflects a response bias toward those with more negative experiences. Regardless, these are areas for health system improvement.

\section{Lessons learned from patient engagement}

Patient involvement in the research improved the study design, including the focal prompt, study inclusion criteria, target population and recruitment strategies. Patient and community groups enabled us to effectively recruit study participants who represented a broad cross-section of Ontarians, including patients living in rural communities and those 
Table 5: Patient and caregiver views on factors affecting the experience of transitioning from hospital to home: discharge process

\begin{tabular}{|c|c|}
\hline Unique concept & Representative quote* \\
\hline \multirow[t]{3}{*}{ Being discharged too early } & $\begin{array}{l}\text { None of us felt [the patient] was ready to leave the hospital but felt he was being pushed out to free up a } \\
\text { bed. (Caregiver of male patient, age 65-79) }\end{array}$ \\
\hline & Discharged too early. I felt I hadn't healed and was afraid of reinjuring. (Male patient, age $65-79$ ) \\
\hline & $\begin{array}{l}\text { Reason for mental health crisis had not been resolved; although the person was no longer in a suicidal } \\
\text { state, they still had suicidal ideation. (Caregiver of male patient, age 50-64) }\end{array}$ \\
\hline \multirow[t]{2}{*}{ Discharge being delayed } & Long wait to be discharged. (Caregiver) \\
\hline & $\begin{array}{l}\text { On the discharge day (Saturday), we waited several hours for the doctor to sign the discharge papers. By } \\
\text { the time she did, the pharmacy was closed, so they had to give us enough for } 24 \text { hours, and we had to } \\
\text { make another trip ( } 20 \text { minutes each way) the next day to fill the prescription. (Caregiver of female patient, } \\
\text { age } \geq 80 \text { ) }\end{array}$ \\
\hline \multirow[t]{3}{*}{$\begin{array}{l}\text { Discharge process being } \\
\text { rushed }\end{array}$} & $\begin{array}{l}\text { Felt a little rushed to leave room as someone was waiting for bed, but staff made sure I understood my } \\
\text { discharge papers. (Female patient, age } 50-64 \text { ) }\end{array}$ \\
\hline & $\begin{array}{l}\text { I had almost no preparation time to leave, it was, like, "Get out of bed, you're going home." (Female patient, } \\
\text { age 19-25) }\end{array}$ \\
\hline & Rushed process, nurse run ragged and [information] passed on in 3 minutes. (Facilitated group participant) \\
\hline \multirow{2}{*}{$\begin{array}{l}\text { Receiving clear and } \\
\text { consistent communication } \\
\text { about health status in } \\
\text { preparation for going home }\end{array}$} & $\begin{array}{l}\text { I was nervous as they still didn't know what [had] caused the horrible leg infection [the patient] had. } \\
\text { (Caregiver of male patient, age 65-79) }\end{array}$ \\
\hline & $\begin{array}{l}\text { The doctors were not honest about [the patient's] prognosis - they [glossed] over it, and the patient did not } \\
\text { fully understand what was happening. (Caregiver of female patient, age 65-79) }\end{array}$ \\
\hline \multirow[t]{2}{*}{$\begin{array}{l}\text { Being involved in discharge } \\
\text { planning }\end{array}$} & $\begin{array}{l}\text { Discharge planning was well done. My mother was involved in her discharge planning, as were her } \\
\text { caregivers. (Caregiver of female patient, age } \geq 80 \text { ) }\end{array}$ \\
\hline & $\begin{array}{l}\text { Family/caregiver were not involved in [patient's] care plan or discharge plan, although [they were] expected } \\
\text { to [provide] support outside hospital and provide housing during crisis. (Caregiver of male patient, age } \\
50-64 \text { ) }\end{array}$ \\
\hline \multirow[t]{2}{*}{$\begin{array}{l}\text { Having short notice of } \\
\text { discharge time }\end{array}$} & $\begin{array}{l}\text { I was notified that same day that my spouse was being discharged and had to arrange to leave work and } \\
\text { pick him up. (Caregiver of male patient, age 65-79) }\end{array}$ \\
\hline & $\begin{array}{l}\text { No warning was given that [the patient] was being discharged; one day it was a week away, the next day it } \\
\text { changed to that day. (Caregiver of female patient, age } \geq 80 \text { ) }\end{array}$ \\
\hline \multirow[t]{2}{*}{$\begin{array}{l}\text { Seeing the doctor at time of } \\
\text { discharge }\end{array}$} & $\begin{array}{l}\text { Did not see the doctor at time of discharge, [which left] many, many unknowns and [added] to fear. (Female } \\
\text { patient, age 26-49) }\end{array}$ \\
\hline & $\begin{array}{l}\text { None of the doctors took the time to tell me anything on discharge. The only doctor who did explain } \\
\text { anything was not present the day of discharge. He had explained a further test I needed before discharge. I } \\
\text { never got the test. (Male patient, age 50-64) }\end{array}$ \\
\hline \multirow[t]{4}{*}{$\begin{array}{l}\text { Having challenges with } \\
\text { transportation home }\end{array}$} & $\begin{array}{l}\text { The person I cared for was unable to get into the car and [couldn't] afford to transfer back home in an } \\
\text { ambulance. (Caregiver of male patient, age } \geq 80 \text { ) }\end{array}$ \\
\hline & $\begin{array}{l}\text { My caregiver wasn't given a wheelchair to put me in to take me to the car. She had to go down to the lobby } \\
\text { to get one and come all the way back up. (Female patient, age 26-49) }\end{array}$ \\
\hline & $\begin{array}{l}\text { I did not have anyone to pick me up or any money to get home. So I had to walk, it was a 5-mile walk. } \\
\text { (Female patient, age 50-64) }\end{array}$ \\
\hline & $\begin{array}{l}\text { Had to drive over } 200 \mathrm{~km} \text { to my home. Travel grant doesn't cover the full cost of an overnight stay. Very } \\
\text { exhausting. (Female patient, age 65-79) }\end{array}$ \\
\hline
\end{tabular}

traditionally underserved. Discussing our early results with patients helped us validate our findings and interpretation. It was clear throughout the process that patients and caregivers identified improving the transition from hospital to home as an important health system priority.

\section{Conclusion}

Our consultation with more than 700 patients and caregivers from diverse communities across the province highlighted 6 key areas affecting their experience of transition from hospital to home: home and community care, the discharge process, medical follow-up after discharge, medications, patient and caregiver education, and the kindness and caring of the health care team in hospital. Most notable were challenges with the timeliness, sufficiency, reliability and consistency of publicly funded home care services. The second phase of our group concept mapping will engage patients and caregivers to prioritize areas for health system improvement. Our work will inform a provincial quality standard on transitions from hospital to home that will be used as a foundation for quality improvement. 
Table 6: Patient and caregiver views on factors affecting the experience of transitioning from hospital to home: patient education

\author{
Unique concept \\ Representative quote*
}

Receiving a written summary of the hospital admission at discharge

After getting a hospital discharge, my father received no discharge instructions. (Caregiver of male patient, age 50-64)

We were provided with a detailed discharge summary that included next steps, including follow-ups, medications and signs to look for re: common complications. (Caregiver of male patient, age $\leq 5$ )

Having contact number(s) of someone to call if there is a problem once home

There was no one I could call once discharged home for the first time to talk about my symptoms. [Having someone to call] might have sent me to the emergency department earlier, thereby avoiding some undue suffering and optimizing my recovery process. (Female patient, age 50-64)

The doctor made sure I had his contact information so that if I experienced any complications or had concerns I could call him. I did have complications from a procedure he performed, and being able to contact him helped me get readmitted to the hospital and treated faster. (Female patient, age 50-64)

Being prepared by hospital staff to manage symptoms There was a good booklet provided about recovery from cardiac surgery, but it would have been great if the most important details were highlighted or individually detailed. (Female patient, age 50-64) and care at home Paucity of information on how to manage care at home (what to watch for in changes, improvement or deterioration). (Caregiver of male patient, age 50-64)

There was little discussion or instructions with family or long-term care about how to care differently for our loved one upon return to long-term care. (Caregiver of male patient, age $\geq 80$ )

${ }^{*}$ Respondent age and gender are provided when available; caregiver respondents provided the age and gender of the patient they were caring for.

Table 7: Patient and caregiver views on factors affecting the experience of transitioning from hospital to home: medications

Unique concept Representative quote*

Medication effects, adverse effects and schedule explained clearly before leaving hospital

No training or support on how to manage complex medication needs once home

Errors about medications on the discharge summary or prescription

Having challenges filling a prescription soon after discharge

No plan for pain management once discharged

Pain medications prescribed at discharge are too strong or not strong enough

Having to pay out of pocket for medications and medical supplies
My medication schedule was explained clearly to me before I left the hospital. (Female patient, age 50-64)

The person I care for did not understand how to take the medications, and no one spent the time explaining. (Caregiver of female patient, age 65-79)

Managing the [medications is] extremely complex when your loved one is dying - more nursing care is required at home. (Caregiver of female patient, age 50-64)

Having to inject medication for yourself is a big responsibility. (Female patient, age 65-79)

After one discharge, the medications on the discharge summary were not correct. (Caregiver)

When I left, I was given 2 inhalers, 1 Ventolin and another bronchial powder inhaler. I was a bit surprised but only noticed a month later that they were both addressed to someone else. (Female patient, age 50-64)

Not able to get discharge prescriptions prior to discharge, no offer to fax to drug store, so by time I got [the patient] home and the analgesic picked up, he was at least 2 hours late in getting [it]! (Caregiver of male patient, age 50-64)

My family member's medications were not readily available at any pharmacy, and she was sent home on a Saturday evening, so hospital outpatient pharmacy closed. (Caregiver of female patient, age 26-49)

[Alternative] treatments other than pain [medications] not considered or offered. (Female patient, age 26-49)

Before leaving, a plan for pain management was not adequately addressed, [such as] dosage ranges to accommodate movement at home versus hospital. (Caregiver of female patient, age 6-18)

My 11-year-old was prescribed morphine for pain. After the first night at home, she had a reaction, so I switched to Children's Advil and she was fine. Why an opioid for a child? (Caregiver of female patient, age 6-18)

My father has been on prescription pain medications for too long. Need support getting him off these drugs given to him by doctors. (Caregiver of male patient, age 65-79)

Cost of medicine or supplies out of pocket are high. (Female patient, age 26-49)

The staff on the floor "forgot" to return patient's [prescribed] medications that we brought in to use because they were not on their formulary ... necessitating extra expense/money to replace these. (Caregiver of female patient, age 65-79)

${ }^{*}$ Respondent age and gender are provided when available; caregiver respondents provided the age and gender of the patient they were caring for. 
Table 8: Patient and caregiver views on factors affecting the experience of transitioning from hospital to home: kindness and caring of health care team in hospital

\author{
Unique concept \\ Representative quote*
}

Hospital staff being kind and caring

Once home, I recalled each day the words of encouragement and advice I had received while in the hospital, to my benefit. (Female patient, age 65-79)

Some of the hospital [physiotherapists] were just going through the motions - did not seem to care. (Male patient, age 65-79)

The doctor was amazing. Caring and kind and treated my 92-year-old dad the same way he would treat a 25-year-old. (Caregiver of male patient, age $\geq 80$ )

Health care team in hospital The nurses, doctors and specialists [took] our concerns seriously since we know our child best. (Caregiver respecting and listening to of male patient, age $\leq 5$ )

caregivers

Not enough weight was given to the concerns of the relatives of the patient. They weren't always included, and the patient, being 85 , did not advocate for the support needed. (Caregiver of female patient, age $\geq 80$ )

Doctors and nurses taking the time to listen and answer questions in hospital

Doctor took time to answer questions and ensure I was equipped to manage on my own. (Female patient, age 26-49)

The doctor and nurses did not answer all my questions and were not helpful with things like what to expect post surgery. (Caregiver of male patient, age 65-79)

Physiotherapy/occupational No [physiotherapy, occupational therapy] or discharge planning on the weekends. (Caregiver of male therapy support being provided in hospital patient, age $\geq 80$ )

[Physiotherapy] made sure I could safely move enough before I was discharged. (Female patient, age 26-49)

Speech, hearing, visual or mobility needs being accommodated in hospital

We felt that the staff did not make sure that their message was heard and understood by our parents. [Our parents'] lack of hearing was not recognized by the hospital staff. (Caregiver of female patient, age $\geq 80$ ) There is no accommodation for someone with aphasia, which is contrary to the [Accessibility for Ontarians with Disabilities Act]. (Caregiver of female patient, age $\geq 80$ )

\title{
Dementia being
}

accommodated and managed appropriately in hospital

Every new nurse working with [the patient] had no idea he [had dementia] and little notion how to accommodate care. Care plan was inadequate or not read. (Caregiver of male patient, age $\geq 80$ ) Nurses at hospital had parent in hospital for over 1 week and did not recognize there were cognitive deficits. (Caregiver of female patient, age $\geq 80$ )

Providing culturally safe and appropriate care for Indigenous people in hospital

Being able to communicate in preferred language in hospital

This was a First Nations patient, and there are unique needs to consider with the history of First Nations' distrust [of] the health care system. (Caregiver)

When I was translating for my dad, the doctor was losing patience with me as I tried to find the right words. (Caregiver of male patient, age 65-79)

No translation services were provided for patient, who did not speak English. (Facilitated group participant)

${ }^{*}$ Respondent age and gender are provided when available; caregiver respondents provided the age and gender of the patient they were caring for.

\section{References}

1. Improving care transitions. Better coordination of patient transfers among care sites and the community could save money and improve the quality of care. [health policy brief]. Health Aff (Millwood) 2012. doi: 10.1377/hpb2012.17.

2. Hansen LO, Young RS, Hinami K, et al. Interventions to reduce 30-day rehospitalization: a systematic review. Ann Intern Med 2011;155:520-8.

3. Naylor MD, Aiken LH, Kurtzman ET, et al. The importance of transitional care in achieving health reform. Health Aff (Millwood) 2011;30:746-54.

4. Joynt KE, Jha AK. Thirty-day readmissions - truth and consequences. N Engl 7 Med 2012;366:1366-9.

5. Krumholz HM, Wang K, Lin Z, et al. Hospital-readmission risk - isolating hospital effects from patient effects. NEngl 7 Med 2017;377:1055-64.

6. Soong C, Bell C. Identifying preventable readmissions: An achievable goal or waiting for Godot? BM7 Qual Saf 2015;24:741-3.

7. Bombard Y, Baker GR, Orlando E, et al. Engaging patients to improve quality of care: a systematic review. Implement Sci 2018;13:98.

8. Carman KL, Dardess P, Maurer M, et al. Patient and family engagement: a framework for understanding the elements and developing interventions and policies. Health Aff (Millwood) 2013;32:223-31.

9. Backman C, Chartrand J, Dingwall O, et al. Effectiveness of person- and family-centered care transition interventions: a systematic review protocol. Syst Rev 2017;6:158.

10. Transitions of care: engaging patients and families. Quick Safety, Issue 18. Oakbrook Terrace (IL): The Joint Commission; 2015:1-3.
11. Population estimates on July 1st, by age and sex. Ottawa: Statistics Canada. Last updated Feb. 13, 2020. Available: https://www150.statcan.gc.ca/t1/tbl1/en/tv. action?pid=1710000501\&pickMembers $\% 5 \mathrm{~B} 0 \% 5 \mathrm{D}=1.7$ \&pickMembers $\% 5 \mathrm{~B} 1 \%$ $5 \mathrm{D}=2.1$ (accessed 2020 Feb. 13).

12. Naylor CD. Health care in Canada: incrementalism under fiscal duress. Health Aff (Millwood) 1999;18:9-26.

13. Burke JG, O'Campo P, Peak GL, et al. An introduction to concept mapping as a participatory public health research method. Qual Health Res 2005;15:1392-410.

14. Kane M, Trochim WM. Concept mapping for planning and evaluation. Thousand Oaks (CA): Sage Publications; 2006.

15. O'Campo P, Burke J, Peak GL, et al. Uncovering neighbourhood influences on intimate partner violence using concept mapping. 7 Epidemiol Community Health 2005;59:603-8.

16. Trochim WM. An introduction to concept mapping for planning and evaluation. Eval Program Plann 1989;12:1-16.

17. Velonis AJ, Molnar A, Lee-Foon N, et al. "One program that could improve health in this neighbourhood is ? ? Using concept mapping to engage communities as part of a health and human services needs assessment. BMC Health Serv Res 2018;18:150.

18. Wilberforce M, Batten E, Challis D, et al. The patient experience in community mental health services for older people: a concept mapping approach to support the development of a new quality measure. BMC Health Serv Res 2018;18:461.

19. Barnert ES, Coller RJ, Nelson BB, et al. A healthy life for a child with medical complexity: 10 domains for conceptualizing health. Pediatrics 2018;142: e20180779. 
20. McCaffrey SA, Chiauzzi E, Chan C, et al. Understanding 'good health care' from the patient's perspective: development of a conceptual model using group concept mapping. Patient 2019;12:83-95

21. LaNoue M, Mills G, Cunningham A, et al. Concept mapping as a method to engage patients in clinical quality improvement. Ann Fam Med 2016;14:370-6.

22. Rising KL, LaNoue M, Gentsch AT, et al. The power of the group: comparison of interviews and group concept mapping for identifying patient-important outcomes of care. BMC Med Res Methodol 2019;19:7.

23. Boyatzis RE. Transforming qualitative information: thematic analysis and code development. Thousand Oaks (CA): Sage Publications; 1998.

24. Saldaña J. The coding manual for qualitative researchers. Thousand Oaks (CA): Sage Publications; 2015.

25. Mills GD, LaNoue M, Gentsch AT, et al. Patient experience and challenges in group concept mapping for clinical research. 7 Patient Rep Outcomes 2019;3:54.

26. Bringing care home: report of the Expert Group on Home and Community Care. Toronto: Ministry of Health and Long-Term Care; 2015. Available: http:// health.gov.on.ca/en/public/programs/lhin/docs/hcc_report.pdf (accessed 2018 Dec. 3).

27. Update: health system integration. Toronto: Ministry of Health and LongTerm Care; 2017. Available: http://health.gov.on.ca/en/news/bulletin/2017/ hb_20170127_10.aspx (accessed 2018 Dec. 3).

28. Thriving at home: a levels of care framework to improve the quality and consistency of home and community care for Ontarians. Toronto: Ministry of Health and Long-Term Care; 2017. Available: http://health.gov.on.ca/en/ public/programs/lhin/docs/loc_report_2017.pdf (accessed 2018 Dec. 3).

29. Dyrstad DN, Testad I, Aase K, et al. A review of the literature on patient participation in transitions of the elderly. Cogn Technol Work 2015;17:15-34

30. Hahn-Goldberg S, Jeffs L, Troup A, et al. "We are doing it together"; the integral role of caregivers in a patient's transition home from the medicine unit. PLoS One 2018;13:e197831.

31. Jeffs L, Saragosa M, Law M, et al. Elucidating the information exchange during interfacility care transitions: insights from a qualitative study. BMF Open 2017;7:e015400

32. Howard-Anderson J, Lonowski S, Vangala S, et al. Readmissions in the era of patient engagement. 7AMA Intern Med 2014;174:1870-2.

33. Kangovi S, Grande D, Meehan P, et al. Perceptions of readmitted patients on the transition from hospital to home. 7 Hosp Med 2012;7:709-12.

34. Dhalla IA, O'Brien T, Ko F, et al. Toward safer transitions: how can we reduce post-discharge adverse events. Healthc Q 2012;15:63-7.

35. Hesselink G, Schoonhoven L, Barach P, et al. Improving patient handovers from hospital to primary care: a systematic review. Ann Intern Med 2012;157:417-28.

36. Kripalani S, LeFevre F, Phillips CO, et al. Deficits in communication and information transfer between hospital-based and primary care physicians: implications for patient safety and continuity of care. 7AMA 2007;297:831-41.

37. Hahn-Goldberg S, Okrainec K, Damba C, et al. Implementing Patient Oriented Discharge Summaries (PODS): a multi-site pilot across early adopter hospitals. Healthc Q 2016;19:42-8.

38. Mitchell SE, Laurens V, Weigel GM, et al. Care transitions from patient and caregiver perspectives. Ann Fam Med 2018;16:225-31.
39. Martin D, Miller AP, Quesnel-Vallée A, et al. Canada's universal health-care system: achieving its potential. Lancet 2018;391:1718-35

Affiliations: Department of Family and Community Medicine (Kiran) St. Michael's Hospital; Department of Family and Community Medicine (Kiran), Institute of Health Policy, Management and Evaluation (Kiran) and Dalla Lana School of Public Health (Devotta, O'Campo), University of Toronto; Centre for Urban Health Solutions (Kiran, Devotta, O'Campo), Li Ka Shing Knowledge Institute of St. Michael's Hospital; Ontario Health (Quality Business Unit) (Kiran, Wells, Kennedy, Mabaya, Phillips, Lang); Department of Medicine (Okrainec), University Health Network and University of Toronto, Toronto, Ont.

Contributors: Tara Kiran conceived the study, and Tara Kiran, David Wells, Amy Lang and Pat O'Campo designed it. Tara Kiran, David Wells and Amy Lang recruited participants and supported data collection. Tara Kiran, David Wells, Karen Okrainec, Carol Kennedy, Kimberly Devotta, Gracia Mabaya, Lacey Phillips and Pat O'Campo analyzed and interpreted the data. Tara Kiran drafted the manuscript. All of the authors revised the manuscript critically for important intellectual content, approved the final version to be published and agreed to be accountable for all aspects of the work.

Funding: Tara Kiran is supported as a Clinician Scientist by the Department of Family and Community Medicine at the University of Toronto and at St. Michael's Hospital. She is also supported by Ontario Health (Quality Business Unit) and the Canadian Institutes of Health Research as an Embedded Clinician Researcher. She is the Fidani Chair in Improvement and Innovation at the University of Toronto.

Acknowledgements: The authors thank their community advisory group for their guidance on study design, support with participant recruitment and assistance with interpreting the data; Health Quality Ontario's Patient, Family and Public Advisors Council for their early input on study design and participation in the study; and Health Quality Ontario's Transitions Between Hospital and Home Quality Standard Advisory Committee for their feedback on study design, recruitment and data interpretation. They thank Health Quality Ontario's Patient and Public Partnering team and Communications team for their work supporting patient and caregiver outreach, and the senior leadership team for their support through the project and helpful comments on the manuscript.

Supplemental information: For reviewer comments and the original submission of this manuscript, please see www.cmajopen.ca/content/8/1/ E121/suppl/DC1. 